Bulletin UASVM Food Science and Technology 70(2)/2013, 99-107

ISSN-L 2344-2344; Print ISSN 2344-2344; Electronic ISSN 2344-5300

\title{
HPLC-UV Analysis Coupled with Chemometry to Identify Phenolic Biomarkers from Medicinal Plants, used as Ingredients in Two Food Supplement Formulas
}

\section{Raluca Maria POP $^{2,3)}$, Florina CSERNATONI ${ }^{1,3)}$, Floricuţa RANGA ${ }^{1 \text { ) }}$, Florinela FETEA ${ }^{1 \text { ), }}$ Carmen SOCACIU ${ }^{1,3 *}$}

${ }^{1)}$ Department of Biochemistry, University of Agricultural Sciences and Veterinary Medicine, Faculty of Food Science and Technology Cluj-Napoca. Romania

${ }^{2)}$ University of Medicine and Pharmacy “ Iuliu Hatieganu” Cluj-Napoca

${ }^{3)}$ BIODIATECH, Research Center for Applied Biotechnology in Diagnosis and Molecular Therapy, Cluj-Napoca, *armen.socaciu@usamvcluj.ro

\begin{abstract}
High performance liquid chromatography (HPLC) with UV detection is nowadays the reference method to identify and quantify the biomarkers of quality and authenticity of plants and food supplements. Six medicinal plants were collected from wild flora: Taraxacum officinalis, Cynara scolimus, Silybum marianum, Hypericum perforatum, Chelidonium majus and Lycopodium clavatum. Two products (A and B) were obtained by mixing individual plant powders; the product A was obtained by mixing dandelion, artichoke and milk thistle, 1:1:1 while product B by mixing St John's wort, Celandine and Wolf's claw, 1:1:1. The methanolic extracts of individual plants as well as three different extracts of products A and B (using acidulated water, neutral water and acidulated methanol) were analyzed using HPLC-UV for their phenolics' fingerprint and composition. The quantitative (targeted analysis) results were further compared using Principal Component Analysis (PCA) in order to identify their specific biomarkers. Thus, quantitative evaluation of individual phenolics in case of individual plants and products $\mathrm{A}$ and $\mathrm{B}$ extracts, showed specific and significant differences of composition. Both products A and B contained elagic acid as major compound. For product A, good biomarkers were trans-cinnamic, chlorogenic, caffeic and $p$ coumaric acids, as well silymarin and silibine originating from milk thistle. For product B, good biomarkers were quercetin and kaempherol, gallic and protocatecuic acids, this product being rich in flavonoids. In conclusion, HPLC-UV coupled with PCA analysis proved to be a rapid and useful way to identify the main biomarkers of plants' authentication, as well of final products' quality and safety.
\end{abstract}

Keywords: medicinal plants, herbal supplements, HPLC fingerprint, Principal Component Analysis

\section{INTRODUCTION}

Among the most important phytochemicals found in medicinal plants are the phenolic derivatives, a large family of secondary metabolites with various roles in plant defense against pathogens and environmental stress, which demonstrated antioxidant activity with beneficial health effects on humans (Rice-Evans et al., 1997; Shahidi and Naczk, 2004; Socaciu et al., 2002, 2009a,b; Scalbert et al., 2005; Halliwell, 2007; Wildman, 2007). Until now, there were elaborated many analytical protocols to separate and identify phenolic acids, flavonoids and their glucosides, catechins, tannins (Santos-Buelga and Williamson, 2003; Prior et al., 2005) or to quantify total phenolics (Singleton, 1999).

In spite of a large variety of medicinal plants still found in Europe, many publications are focused more on the evaluation of Asian or South-American wild plants and few data are 
available about the medicinal herbs from Central-East European regions. Standardization according to EU legislation of herbal supplements needs adequate authentication and quality control (Wichtl, 2004). In this context, our previous studies were directed towards the use of advanced and rapid methods to fingerprint botanical supplements, to authentify and quantify the key-molecules of medicinal plants, namely phenolic acids derivatives and flavonoids as "bioactive components" of these products (Socaciu et al., 2009a, Pop et al., 2013).

Some Romanian herbs (Echinaceea, lavender, lemon balm, sage, oregano rosemary, thyme, mint, St John's wort) were investigated for their total phenolic content and antioxidant activity (Socaciu 2009b; Spiridon et al., 2011). Also, different herbal medicines e.g. dandelion, artichocke, milk thistle, St John's wort, celandine and wolf's claw which claim to have hepatoprotective potential based on the long, traditional use of their ingredients were investigated (Zavoi et al., 2011). Among above listed medicinal plants, dandelion (Taraxacum officinalis) is an old remedy in the therapy of liver diseases due to „taraxacin” a mixture of eudesmanolide and germacranolide derivatives. Its composition in phenolics (phenolic acids and 7-D glucosides of apigenol and luteolin) was also reported (Schütz et al., 2005). Artichocke (Cynara scolimus) is known to contain cynarin, a phenolic colagogue (Wang et al., 2003). Milk thistle (Silybum marianum) is known to be hepatocyte activator due to „silymarin”, a mixture of flavolignans (silybine, silicristine and silidianine) and taxifolin, a dihydroquercetin (Ding et al., 2001; Minakhmetov et al., 2001). St John's wort (Hypericum perforatum) has various pharmacological properties (antidepressive, antiviral, antibacterial, liver protective), due to hypericins (condensed anthraquinones), hyperforin and phenolics, mainly rutinoside and condensed tannins (Mulinacci et al., 1999; Barnes et al., 2001). Celandine (Chelidonium majus) is a source of chelidonin, a naftophenantridin with colecystokinetic, antispastic, antihepatotoxic and anticancerigenic effects, recommended in cyrosis and chronic hepatitis, without known data on phenolics' content. Wolf's claw (Lycopodium clavatum) contains alkaloids and lignans whose structure and pharmacologic effects are not yet elucidated, beside alkaloids and triterpenoids, as well nicotine and flavonoids with good effects on liver tumor inhibition, anti-inflamatory and antimicrobial action. Phenolic acids were also reported in older references article (Pedersen and Øllgaard, 1982) as products of lignin degradation, such as chlorogenic syringic, $p$-hydroxybenzoic, vanillic, $p$-coumaric and ferulic acids, lactones and ketones.

The high performance liquid chromatography represents the best technique used nowadays to separate, to fingerprint qualitatively and to identify and/or quantify each molecule from complex mixtures as is it the case of plant extracts and herbal supplements (Fan et al., 2006; Gong et al., 2006, 2009; Giri et al., 2010; Nollet and Toldra, 2012; Mattoli et al., 2011).

Therefore, we applied HPLC coupled with UV detection to identify and quantify the main phenolic derivatives in two herbal supplements containing six medicinal plant ingredients, in order to identify the most relevant biomarkers of authenticity, quality and traceability. The qualitative fingerprints were correlated with the quantitative composition for each plant or products, using Principal Component Analysis.

\section{MATERIALS AND METHODS}

\section{Plant materials and sample preparation}

Six medicinal plants were collected from wild flora: Taraxacum officinalis (Dandelion), Cynara scolimus (Artichoke), Silybum marianum (Milk thistle), Hypericum perforatum (St John's wort), Chelidonium majus (Celandine), Lycopodium clavatum (Wolf's claw). Two 
products were obtained by mixing plant powders: $\mathrm{A}=$ mix of dandelion, artichoke and milk thistle, 1:1:1 and B= mix of St John's wort, Celandine and Wolf's claw, 1:1:1.

Three types of extracts were prepared, containing either $15 \%$ individual plant powders or $15 \%$ product $\mathrm{A}$ or $\mathrm{B}$, in: acidic water with addition of $10 \%$ ascorbic acid (a), hot distilled water (b) and methanol with $1 \%$ addition of $\mathrm{HCl}$ (c). All three extracts (a, b and c) were comparatively investigated after sonication for their HPLC fingerprints and quantified according to calibration with pure standards.

The products $\mathrm{A}$ and $\mathrm{B}$ were formulated as encapsulated powders with a mean weight of $0,20 \mathrm{~g}(\mathrm{~A})$ and $0,27 \mathrm{~g} \mathrm{(B)}$ and were recommended to have coleretic and colagogue effects (A) and antioxidant and hepatoprotective capacity (B). The total content of phenolics (determined by spectroscopy based on Folin Ciocilteu method), expressed in gallic acid equivalents (GAE) was $1850 \mathrm{mg}$ GAE/ 100g powder A and $1260 \mathrm{mg}$ GAE /100 g powder B.

\section{HPLC-UV analysis}

All methanolic extracts from individual plants and extracts a, b or c of herbal supplements A and B were filtered (Millipore $0.45 \mu \mathrm{m}$ ) and injected in the HPLC column (Supelcosil LC 18, $25 \mathrm{~cm} \mathrm{x} \mathrm{4,6} \mathrm{mm} \mathrm{x} 5 \mu \mathrm{m}$ ), at $25^{\circ} \mathrm{C}$, using $20 \mu \mathrm{l}$ from each sample.

The HPLC separation was made on an Agilent 1200 HPLC device with a solvent mixture A and B as follows: methanol: acetic acid: water (10:2:88) (solvent A) and methanol: acetic acid: water (90:3:7) (solvent $\mathrm{B}$ ) at a flow of $1 \mathrm{~mL} / \mathrm{min}$ and detection at $280 \mathrm{~nm}$. The solvent A/B gradient applied was as follows: A from $100 \%$ to $85 \%$ (min $0-10$ ), A from $85 \%$ to $50 \%$ (min $10-30$ ), A from $50 \%$ to $15 \%$ (min $30-45$ ), A from $15 \%$ to $100 \%$ (min $45-55$ ).

The identification of peaks was made by comparison with HPLC chromatograms of individual, pure phenolic acids (gallic, protocatecuic, chlorogenic $=5$-caffeoyl quinic acid, caffeic, $o$ - and $p$-coumaric, trans-cinnamic, vanillic, ferrulic and synaptic acids) cynarin, flavonoid derivatives (quercetin, kaempherol, taxifolin, apigenin glucoside), the pure standards of these molecules being provided from Sigma Aldrich.

To evaluate the phenolic concentration in each type of extracts, Gallic acid (GA) was used in a concentration range from 10 to $1000 \mathrm{mg} / 100 \mathrm{~mL}$ extract, to calibrate the HPLC analysis $\left(r^{2}=0.992\right)$. By comparison of peak areas with GA peak areas, the concentrations of individual phenolics in each plant and product were expressed as mg GAE / $100 \mathrm{~g}$ dry product.

\section{Statistical Analysis}

The data were compared by chemometry (Principal Component analysis), using Unscrambler X10.1. (CAMO software license). Targeted analysis was used to compare the medicinal plants used as ingredients of products $\mathrm{A}$ and $\mathrm{B}$, and to compare the plants with the obtained products. Thus, targeted analysis was made using the HPLC areas of the main compounds identified in the chromatograms when medicinal plants were compared and using the phenolic acid concentrations when both plants and products obtained thereof were compared.

\section{RESULTS AND DISCUSSION}

\section{HPLC-UV analysis of individual plants used as ingredients comparatively to products A and $B$}

Fig. 1 represents the HPLC-UV chromatograms $(280 \mathrm{~nm})$ of methanolic extracts (c) of the four representative plants (Dandelion, Artichocke, Milk thistle, St John's wort) used as 
ingredients to obtain the two products A and B. The peak identification was made comparatively with pure standards, as described in Materials and methods.

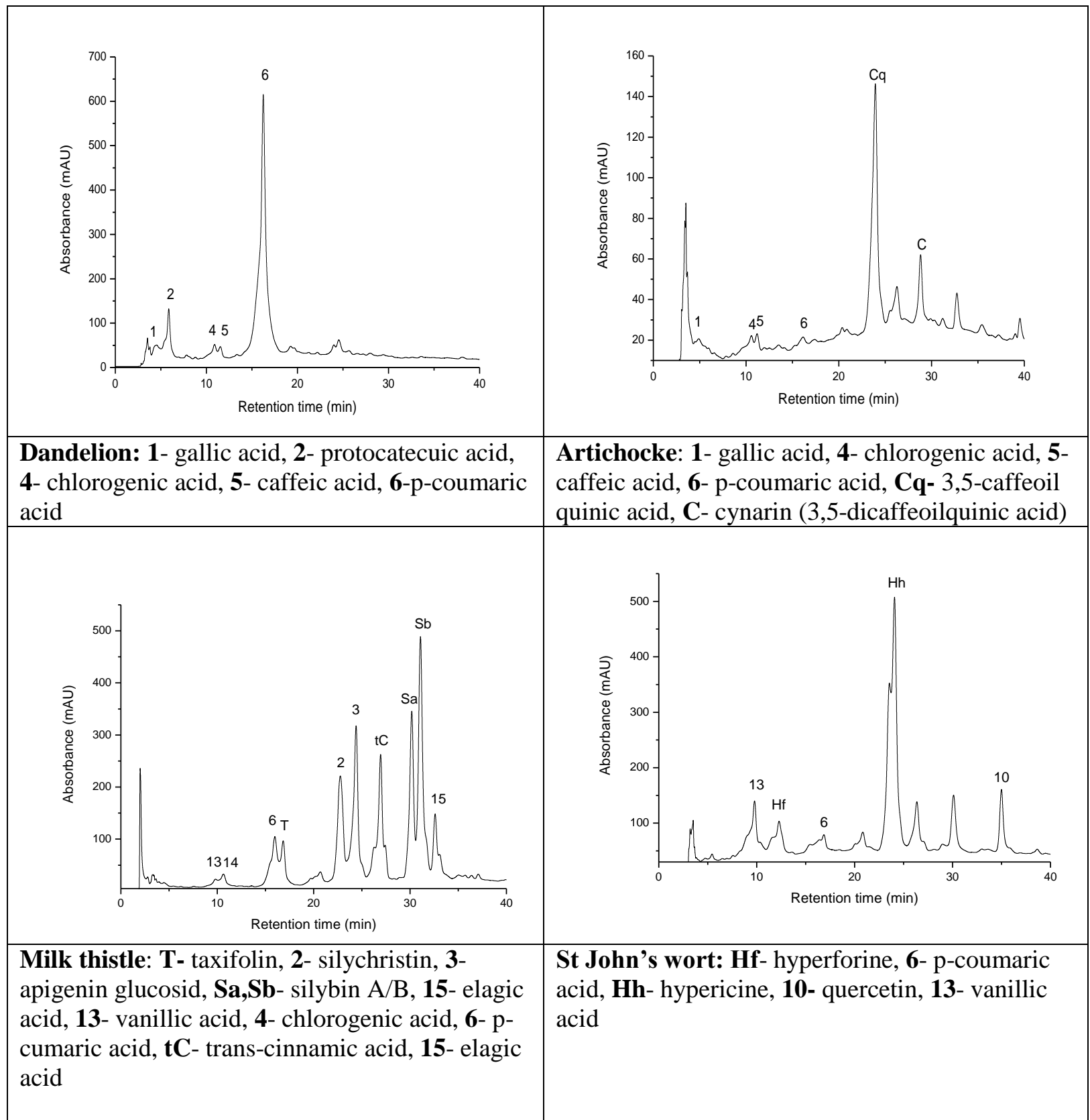

Fig.1. HPLC-UV chromatograms $(280 \mathrm{~nm})$ of methanolic extracts (c) of Dandelion, Artichocke, Milk thistle, St John's wort, used as ingredients for products A and B

In the Dandelion extract there were identified few phenolic acids: gallic and protocatecuic acid, chlorogenic and caffeic acid (peaks 1-5), p-coumaric acid being the major peak (6) and biomarker. The Artichocke extract contained as major components cynarin (C) and 3,5-caffeoil quinic acids (Cq), beside the phenolic acids (peaks 1-6). Multiple peaks were 
identified in Milk thistle corresponding to taxifolin (T), silychristin (2), apigenin glucoside (3), Silybin A and B (Sa, Sb) and elagic acid (15).

In the St John's wort extract there were identified vanillic acid (13), hypericine (Hh), pcoumaric acid (6), hiperforine (Hf) and quercetin (10). Celandine extract contained a complex mixture of caffeic acid, $o$-coumaric acid, trans-cinnamic acid and flavonoid derivatives while the extract of wolf's claw contained vanillic acid, $p$-cumaric acid, trans-cinnamic acid, ferulic acid, syringic acid and quercetin (unpublished data).

Fig. 2 represents the HPLC fingerprint of products $\mathrm{A}$ in solvent c. The main peaks identified in the chromatogram of product A corresponded to all plants mixed used as ingredients: gallic acid (1), chlorogenic acid (4), caffeic acid (5), $p$-coumaric acid (6), taxifolin (T), silychristin (2), apigenin glucoside (3) and caffeoyl quinic acids (Cq), Silybin A and B (Sa, Sb) and elagic acid (15). The authenticity biomarkers of this product are mainly originating from artichocke and milk thistle. Product B contained elagic acid as major compound. Comparing with Product A, Product B contained also protocatecuic, p-OH benzoic, vanillic, syringic and $\mathrm{p}-\mathrm{OH}$ cinamic acids, mainly originating from wolf's claw.

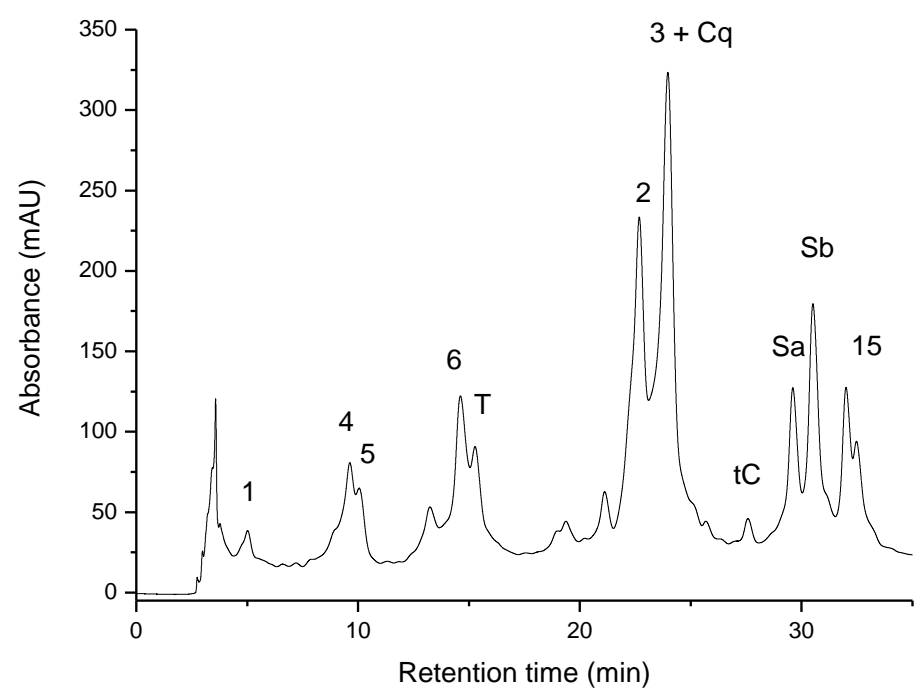

Fig.2. HPLC-UV chromatograms of methanolic extracts (c) of product A registered at $280 \mathrm{~nm}$, where 1- gallic acid, 4- chlorogenic, 5- caffeic, T- taxifolin, 2- silychristin, 6- p-coumaric, 3+Cq- apigenin glucoside + caffeoylquinic acid; Sa, Sb- silibin A and B, 15- elagic acid

\section{Evaluation of phenolic acids from individual plants and products (A and B) in methanol extracts (c)}

Considering that solvent $\mathrm{c}$ was the most efficient in extracting phenolics, the methanolic extract was further used to quantify the concentration of individual phenolic acids in different plants. Table 1 represents the phenolic acids concentration mean values, expressed in mg GAE/ $100 \mathrm{~g}$ dry plant, as determined after calibration by HPLC-UV. 
Tab. 1

Concentrations of individual phenolic acids (expressed as mg GAE/100 g dry plant)

\begin{tabular}{|c|c|c|c|c|c|c|c|c|c|}
\hline \multirow{2}{*}{$\begin{array}{l}\mathrm{t}_{\mathrm{R}} \\
\min \end{array}$} & \multirow{2}{*}{$\begin{array}{ll}\text { Name } & \text { of } \\
\text { phenolic } & \\
\text { derivative } & \end{array}$} & \multicolumn{8}{|c|}{ mg GAE/100 g dry plant } \\
\hline & & $\begin{array}{l}\text { Dande } \\
\text { lion }\end{array}$ & Artichoke & Celandine & $\begin{array}{c}\text { St } \\
\text { John's } \\
\text { wort }\end{array}$ & $\begin{array}{l}\text { Milk } \\
\text { thistle }\end{array}$ & $\begin{array}{l}\text { Wolf's } \\
\text { claw }\end{array}$ & $\begin{array}{l}\text { Product } \\
\text { A }\end{array}$ & $\begin{array}{c}\text { Product } \\
\text { B }\end{array}$ \\
\hline 4.54 & Gallic Acid & 43.25 & 23.08 & 37.48 & - & - & 8.48 & 64.11 & 52.76 \\
\hline 6.15 & $\begin{array}{l}\text { Protocatecuic } \\
\text { Acid }\end{array}$ & 112.64 & - & 67.75 & - & - & 26.11 & - & 50.60 \\
\hline 7,43 & $\begin{array}{l}\text { p-OH Benzoic } \\
\text { Acid }\end{array}$ & - & - & - & - & - & 12.91 & - & 10.08 \\
\hline 9.35 & Vanillic Acid & - & - & - & 150.4 & 14.99 & 25.30 & - & 9.27 \\
\hline 11.05 & $\begin{array}{l}\text { Chlorogenic } \\
\text { Acid }\end{array}$ & 59.89 & 35.81 & 41.40 & - & 24.24 & 14.92 & 96.15 & 43.87 \\
\hline 11.40 & Syringic Acid & - & - & - & - & - & - & - & 1.77 \\
\hline 11.85 & Caffeic Acid & 31.15 & 13.36 & 27.45 & - & - & 11.81 & 46.02 & 12.12 \\
\hline 14.36 & $\begin{array}{ll}\text { p-OH } & \text { Cinamic } \\
\text { Acid } & \end{array}$ & - & - & - & - & - & 21.50 & - & 1.88 \\
\hline 16.42 & p-Coumaric Acid & 220.10 & 13.43 & -- & 78.74 & 17.10 & 9.22 & 35.75 & 4.22 \\
\hline 18.44 & Ferulic Acid & - & - & - & - & - & 7.97 & - & - \\
\hline 18.53 & $\begin{array}{l}\mathrm{o}-\mathrm{OH} \\
\text { Cinnamic Acid }\end{array}$ & - & - & - & - & - & - & - & - \\
\hline 19.54 & Sinapic Acid & - & - & - & - & - & 48.81 & - & - \\
\hline 21.47 & $o$-Coumaric Acid & - & - & 10.19 & - & - & - & - & - \\
\hline 23.45 & $\begin{array}{l}\text { trans-Cinnamic } \\
\text { Acid }\end{array}$ & - & 54.25 & - & - & 59.80 & - & 66.07 & - \\
\hline 24.93 & Elagic Acid & 48.38 & - & 93.86 & - & 229.6 & 49.68 & 330.95 & 315.50 \\
\hline
\end{tabular}

Dandelion was rich in polar phenolics, especially in p-coumaric and chlorogenic acid. St John's wort was easy to differentiate based on its high concentrations of vanillic and $p$-coumaric acid. Artichocke and wolf's claw had higher concentrations of polar phenolic derivatives (especially high content of elagic, synapic acids and cynarin respectively), although the total concentration of phenolics was low. Celandine and Milk thistle contained elagic, gallic and protocatecuic acids, and also unpolar derivatives.

Product A contained as major compound elagic acid, at $330.95 \mathrm{mg} / 100 \mathrm{~g}$ product identified only in solvent $c$, therefore consider to be a good biomarker of product A, beside transcinnamic acid. Also, the presence of silimarine and silibine (not-quantified) can be good biomarkers, originating from milk thistle, as well caffeic and para-coumaric acids.

Product B contained beside gallic and protocatecuic acids (found in equivalent quantities in solvents a and b), quercetin and kaempherol as major component in the solvent $\mathrm{c}$.

As a remark, the methanolic extract $c$ of product B was richer in flavonoids (quercetin and kaemferol) even if generally it was poor in phenolics. Solvent $a$ (water with $1 \%$ ascorbic acid) extracted preferentially polar phenolics mainly gallic, protocatecuic and clorogenic acids, in both A and B products. Solvent $b$ (water) extracted same phenolics in product A but more in B, namely vanilic, para-benzoic, para-cumaric and syringic acid. Solvent $c$ (acidic methanol) extracted qualitatively and quantitatively the largest variety of phenolics, e.g. 6 compounds from product $\mathrm{A}$ and 11 compounds in product $\mathrm{B}$. 


\section{Chemometry by Principal Component Analysis}

The discrimination between the medicinal plants used as ingredients for products $\mathrm{A}$ and $\mathrm{B}$ and the identification of phenolic acid biomarkers specific for both plants and products A and $\mathrm{B}$ is represented in Fig. $3 \mathrm{a}$ and $\mathrm{b}$ respectively. In the first case, when HPLC areas were used the score plots generated by the comparison of $\mathrm{PC} 1$ and $\mathrm{PC} 2$ accounted $77 \%$ of the total variance (Fig. 3a) and $82 \%$ of the total variance (Fig. 3b) when phenolic acid concentrations were used.
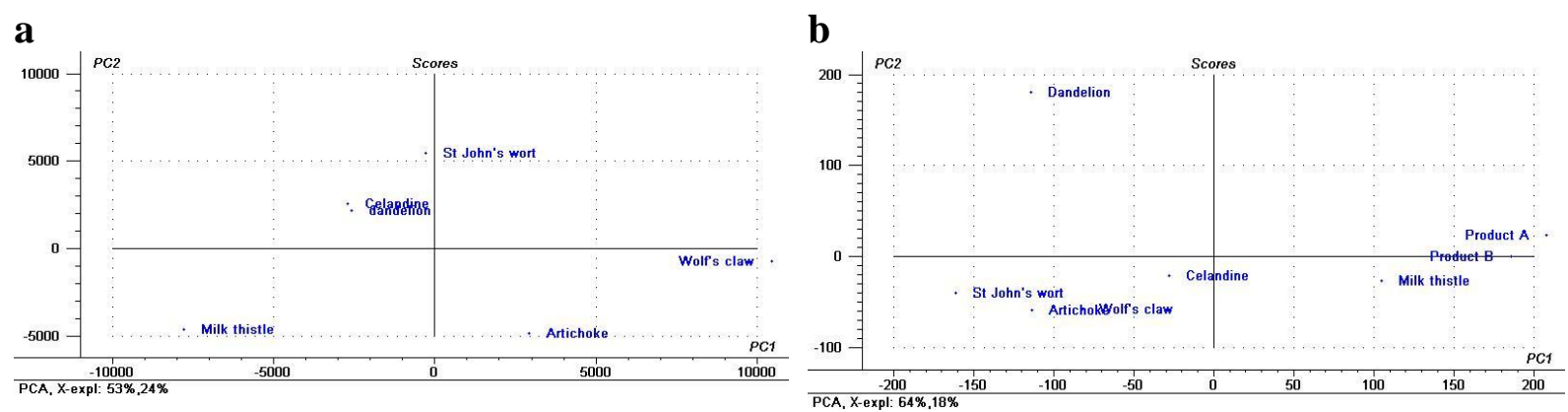

Fig. 3. Targeted PCA analysis of data, based on HPLC peak areas (a) and concentrations of phenolic acid compounds (b)

In both cases, the group distribution was done almost exclusively along PC1 axis. In the first case, the medicinal plants were clustered into five groups indicating the similar composition of celadine and dandelion which were situated very close to each other. In the other case, the plants and the two products were clustered into four groups. The first group represented by Products A, Product B and Milk thistle is negatively correlated with Celadine group and St John's wort, Artichoke and Wolf's claw group situated at the right side of the plot. Dandelion group opposite to the other three groups is situated at the top of the positive PC2 axis. The superposition of score and loading plots (data not shown) indicates that plant group differentiation was due mainly to elagic acid, trans-cinnamic acid, protocatecuic acid, quercetin and vanillic acid. Regarding the discrimination between the plants and Products A and B, the phenolic acid biomarkers responsible for sample grouping were elagic, $p$-coumaric, protocatecuic, chlorogenic, caffeic and vanillic acids.

\section{CONCLUSION}

HPLC-UV method proved to be a useful tool to fingerprint individual medicinal plants used as ingredients for herbal supplements (products A and B), based on their composition in phenolic acid derivatives and other phytochemicals (flavonoids, hypericine, stilbenes, etc.).

Depending on the solvent polarity (acidified water $v s$ water $v s$ acidified methanol), the phenolic pattern of individual plant extracts or of herbal products A and B was different, showing that methanolic extract induced the best extraction yield and more complex composition of phenolics.

The quantitative evaluation of individual phenolics of products plant ingredients, products $\mathrm{A}$ and $\mathrm{B}$, showed specific and significant differentiations among plants and products, useful for their authentication. 
Both products $\mathrm{A}$ and $\mathrm{B}$ contained elagic acid as major compound. For product A, good biomarkers were trans-cinnamic, chlorogenic, caffeic and para-coumaric acids, as well silimarine and silibine originating from milk thistle. For product B, good biomarkers were quercetin, kaempherol, gallic and protocatecuic acids, this product being rich in flavonoids.

Based on the quantitative composition of phenolic acids, targeted PCA analysis showed good discriminations between plants and products.

\section{REFERENCES}

1. Barnes, J., L.A. Anderson and J.D. Philippson (2001). St. John's wort (Hypericum perforatum L): a review of its chemistry, pharmacology and clinical properties. J. Pharmacol. 53: 583-600.

2. Ding, T., S. Tian, Z. Zhang, D. Gu, Y. Chen, Y. Shi and Z. Sun (2001). Determination of active component in silymarin by RP-LC and LC/MS. J Pharm. Biomed. Anal. 26:156-201.

3. Fan, X.H., Y.Y. Cheng, Z.L. Ye, R.C. Lin and Z.Z. Qian (2006). Multiple chromatographic fingerprinting and its application to the quality control of herbal medicines. Anal. Chim. Acta. 555:217224.

4. Giri, L., H.C. Andola, V.K. Purohit, M.S.M. Rawat, R.S. Rawal and I.D. Bhatt (2010). Chromatographic and spectral fingerprinting standardization of traditional medicines: an overview as modern tools. Res. J. Phytochem. 4:234-241.

5. Gong, F., B.T. Wang, Y.Z. Liang, F.T. Chau and Y.S. Fung (2006). Variable selection for discriminating herbal medicines with chromatographic fingerprints. Anal. Chim. Acta. 572:265-271.

6. Gong, F., Q. Zhang and J. Zhang (2009). Quality Assessment of Herbal Medicine with Chromatographic Fingerprint, J Drug Addition, Education and Eradication 4: 257-302.

7. Halliwell, B. (2007). Dietary polyphenols: Good, bad, or indifferent for your health? Cardiovascular Res.73:341-347.

8. Mattoli, L., F. Cangi, C. Ghiara, M. Burico, A. Maidecchi, E. Bianchi, E. Ragazzi, L. Bellotto, R. Seraglia and P. Traldi (2011). A metabolite fingerprinting for the characterization of commercial botanical dietary supplements. Metabolomics. 7:437-445.

9. Minakhmetov, R.A., L.A. Onuchak, L. Kurkin, E.V. Avdeeva and A.V. Volotsueva (2001). Analysis of Flavonoids in Silybum marianum Fruit by HPLC. Chem. Nat. Comp. 37:318-321.

10.Mulinacci, N., C. Bardazzi, A. Romani, P. Pinelli, F.F. Vincieri and A. Costantini (1999). HPLC-DAD and TLC-Densitometry for quantification of hypericin in Hypericum perforatum L. Extracts. Chromatographia 49: 197-201.

11.Nollet, L. M.L. and F. Toldra (2012). Food Analysis by HPLC, Third Edition, CRC Press, US.

12.Pedersen, J.A. and B. Øllgaard (1982). Phenolic acids in the genus Lycopodium. Biochem. Systematics and Ecology 10:3-9.

13.Pop, R.M., C. Socaciu, A. Pintea, A.D. Buzoianu, M.G. Sanders, H. Gruppen and J.P.Vincken (2013). UHPLC-PDA/ESI-MS analysis of the main berry and leaf flavonol glycosides from different Carpathian's Hippophae rhamnoides L. varieties. Phytochem Anal, 24(5):484-92.

14.Prior L.R., X. Wu and K. Schaich (2005). Standardized methods for the determination of antioxidant capacity and phenolics in foods and dietary supplements. J. of Agric. Food Chem. 53(10): $4290-4302$.

15.Rice-Evans, C.A., N. Miller and G. Paganga (1997). Antioxidant properties of phenolic compounds. Trends Plant Sci. 2: 152-159.

16.Santos-Buelga, C. and G. Williamson (Eds.) (2003). Methods in polyphenol analysis. The Royal Society of Chemistry, Cambridge.

17.Scalbert, A., C.M. Morand, C. Rémésy and L. Jiménez (2005). Dietary polyphenols and the prevention of diseases. Crit. Rev. Food Sci. Nutr. 45: 287-306. 
18.Schütz, K., D.R. Kammerer, R. Carle and A. Schieber (2005). Characterization of phenolic acids and flavonoids in dandelion (Taraxacum officinale) root and herb by high-performance liquid chromatography/electrospray ionization mass spectrometry. Rapid Commun. Mass Spectrom. 19:179186.

19.Shahidi, F. and M. Naczk (2004). Phenolics in Food and Nutraceuticals, CRC Press, Taylor \& Francis, US.

20.Singleton, V.L., R. Orthofer and R.M. Lamuela-Raventos (1999). Analysis of total phenols and other oxidation substrates and antioxidants by means of Folin-Ciocalteu reagent. Methods Enzymol. 299:152-178.

21. Socaciu C. (2002) Antioxidant Phytochemicals: chemical characterization, function and actions, Bul.USAMV- A, 57: 22-29.

22. Socaciu C. (2009a). Antioxidanţi fitochimici, p. 95-127. In: Dragan S., I. Gergen and C. Socaciu (Eds.). Alimentaţia funcţională cu componente bioactive naturale în sindromul metabolic. Eurostampa.

23. Socaciu, C., F. Ranga, F. Fetea, L. Leopold, F. Dulf and R. Parlog (2009b). Complementary advanced techniques applied for plant and food Authentication. Czech J. Food Sci. 27:S70-S75.

24.Spiridon, I., R. Bodirlau and C.A. Teaca (2011). Total phenolic content and antioxidant activity of plants used in traditional Romanian herbal medicine. Central Eur.J. Biol. 6: 388-396.

25.Wang, M.F., J.E. Simon, I.F. Aviles, K. He, Q.Y. Zheng and Y. Tadmor (2003). Analysis of antioxidative phenolic compounds in artichoke Cynara scolymus L. J. Agr. Food Chem. 51:601-608.

26.Wichtl, M. (2004). Herbal drugs and phytopharmaceuticals. $3^{\text {rd }}$ ed. Boca Raton: Medpharm.

27.Wildman, R.E.C. (2007). Handbook of Nutraceuticals and Functional Food, CRC Press, Taylor \& Francis, US.

28.Zavoi, S., F.Fetea, F.Ranga, R.Pop, A.Baciu and C.Socaciu (2011). Comparative fingerprint and extraction yield of medicinal herb phenolics with hepatoprotective potential, as determined by UV-Vis and FT-MIR spectroscopy. Not. Bot. Horti Agrobo. 39(2): 82-89. 